\title{
Pesca artesanal en la Isla de San Andrés: entre la cooperación y el cooperativismo
}

\author{
Artisanal fishing on the island of San Andrés: between \\ cooperation and cooperativism
}

Antonio Olmos Pinzón ${ }^{1}$

\section{Resumen}

El presente trabajo estudia la cooperación que sustenta la permanencia de la pesca artesanal de San Andrés en las cooperativas y asociaciones. Dicha cooperación se entiende como un valor que denota acción colectiva en torno a objetivos comunes. La metodología propuesta se basó, en primer lugar, en revisión bibliográfica que da cuenta de algunos factores históricos que han configurado las condiciones de la pesca artesanal, tales como las trayectorias de especialización e institucionalización de la pesca y las continuidades socioculturales vigentes en las relaciones sociales entre pescadores. En segundo lugar, en un estudio de caso en la cooperativa de pescadores artesanales "Coopesbi", se identifican normas, roles y valores que emergen de la práctica de la pesca. Se encontró que la cooperación está atravesada por lógicas que conjugan pautas de conducta provenientes tanto del cooperativismo como de los marcos históricos y normativos de la pesca artesanal. En este sentido, se presenta un análisis sobre la forma como el cooperativismo ha sido apropiado e hibridado por los pescadores artesanales de San Andrés.

Palabras clave: Pescadores artesanales; Isla de San Andrés; Cooperación; Cooperativismo

Tipología: Artículo de investigación

Recibido: $10 / 07 / 2018$

Evaluado: $1 / 05 / 2019$

Aceptado: 30/05/2019

Disponible en línea: 31/05/2019

Como citar este artículo: Olmos-Pinzón, Antonio. Pesca artesanal en la Isla de San Andrés: entre la cooperación y el cooperativismo. Jangwa Pana, 18 (2), 284-303. Doi: http://dx.doi.org/10.21676/16574923.2995

\footnotetext{
${ }^{1}$ Antropólogo de la Universidad Nacional de Colombia. Actualmente estudiante de la maestría en Estudios Interdisciplinarios sobre Desarrollo de la Universidad de los Andes y tutor del Centro de Español de la misma universidad. Correo electrónico: a.olmos@uniandes.edu.co. ORCID ID: 0000-0003-3698-6329.
} 


\begin{abstract}
This work studies the cooperation that sustains artisanal fisheries of San Andrés in cooperatives and associations. This cooperation was understood as a value that denotes collective action around common objectives. The proposed methodology was based, firstly, on a bibliographic review that gave an account of some historical factors that have shaped the conditions of artisanal fishing, such as the trajectories of specialization and institutionalization of fishing and the current sociocultural continuities in social relations between fishermen. Secondly, was based in a case study in the cooperative of artisanal fishermen "Coopesbi", identifying norms, roles and values that emerge from the practice of fishing. It was found that cooperation is crossed by logics that combine patterns of behavior coming from both cooperativism and the historical and normative frameworks of artisanal fishing. In this sense, an analysis is presented on the way in which cooperativism has been appropriated and hybridated by the artisanal fishermen of San Andrés.
\end{abstract}

Key words: Fishermen; San Andres Island; Cooperation; Cooperativism.

\section{Introducción}

La pesca artesanal es una práctica tradicional de los pobladores de la isla de San Andrés. Esta ha representado un fuerte vínculo entre los isleños y el mar, y tiene gran relevancia para la economía local. Si bien apenas representa el 2,3 $\%$ del PIB departamental (Aguilera-Díaz, 2010), cumple un papel muy importante para el ingreso de divisas, la generación de empleo transitorio y permanente, y la seguridad alimentaria de la isla. La producción pesquera artesanal es destinada casi en un $70 \%$ al consumo interno (Agámez, 2004), con diversidad de especies marinas como langostas, caracoles pala, pargos, meros, chermas, sierras, jureles, dorados, atunes, barracudas, entre otros (Pedraza, 2018). Esto resulta muy relevante para San Andrés, en donde se produce muy poco alimento y la mayor parte del alimento es traído de afuera.

Esta isla oceánica tiene una extensión de 27 kilómetros cuadrados y está ubicada en el Caribe suroccidental, a 480 kilómetros de la Colombia continental y a 180 kilómetros de la costa de Centro América. Está rodeada por una serie de cayos y bancos coralinos con gran importancia económica y ecosistémica (Aguilera, 2010). Antes de mediados del siglo XX, las interacciones económicas y culturales de San Andrés con Colombia continental fueron muy limitadas (Meisel-Roca, 2003). Hasta entonces, los pobladores eran descendientes de plantadores puritanos ingleses y esclavos africanos provenientes de Jamaica que poblaron San Andrés y Providencia a fines del siglo XVIII. Esta situación cambió dramáticamente con la declaratoria de Puerto Libre en 1953 que provocó la instauración de dinámicas comerciales y turísticas, y la llegada masiva de turistas e inmigrantes. Esta isla pasó de tener una población de 3.705 habitantes en 1951 a 20.359 en 1973. En el 2005, según el Departamento Administrativo de Nacional de Estadística (DANE), la población de San Andrés ascendía a 70.554 habitantes. De esos, el $57 \%$ eran raizales, es decir, con características culturales únicas y lengua propia. Los raizales, considerados como el pueblo ancestral de la isla, tienen una identidad angloafricana, practican principalmente la religión bautista y tienen como lengua el "inglés creole". Por su parte, el $43 \%$ restante son mestizos y blancos, con ascendencia -mayoritariamente- colombiana y -en menor medida- sirio-libanesa.

Antes de mitad del siglo XX la pesca era usada exclusivamente para el autoconsumo y el 
intercambio. Después, con la declaratoria de Puerto Libre en San Andrés y mediante un proceso paulatino de especialización y tecnificación, la pesca se convirtió en una actividad con mayor participación en la economía monetaria (Márquez, 2005). En este proceso de cambio apareció el cooperativismo como un modelo de organización social a partir del cual los pescadores podían asociarse entre ellos, establecer unas reglas de mercado justas, acceder a beneficios colectivos y crear organizaciones como plataformas de representación ante el Estado. Este modelo fue exigido por las entidades gubernamentales y acogido por la mayoría de pescadores que se especializaron. Desde los años sesenta, el Gobierno empezó a promover la tecnificación de la pesca artesanal con apoyo de organizaciones internacionales como la FAO, con el objetivo de aumentar la producción. Las innovaciones tecnológicas fueron promovidas por varias instituciones del Estado tales como el Inderena, el INPA y el ICA (Márquez 2014, p. 85). Estas entidades exigían la pertenencia de los pescadores a una organización de base, para la transferencia de nuevas tecnologías como lanchas y motores (Rosberg, 1980). A partir de entonces, los pescadores empezaron a conformar cooperativas y asociaciones.

Según el Plan de Desarrollo 2012-2015 (Gobernación de San Andrés Providencia y Santa Catalina [GSAPSC], 2012), se encuentran registrados como pescadores artesanales un total de 812 personas, de los cuales 191 son los más regulares. Del total de pescadores, el $87 \%$ son raizales, a pesar de que en la isla el grupo raizal representa menos de la mitad de la población total. El hecho de que ellos todavía sean el grupo predominante en la pesca artesanal evidencia que se conservan vínculos con la sabiduría ancestral, pues actividades como la navegación, la agricultura y la pesca han existido desde la llegada de los pobladores fundadores en el siglo XVII.

El $98 \%$ de los pescadores está vinculado a una organización de base. Existen cuatro cooperativas, una asociación mutual y seis asociaciones (Secretaría de Agricultura y Pesca, 2014). Si bien casi todos los pescadores pertenecen a alguna organización cooperativista, la pesca artesanal en San Andrés se realiza de manera independiente en la medida en que no depende de la asociatividad formal y, en su mayor parte, es realizada con aparejos y embarcaciones propias. De ahí que una de las preguntas que guio el presente trabajo fue cómo dicha institucionalidad ha sido apropiada, resignificada, reformulada o hibridada por los pescadores.

Particularmente, esta investigación se interesó por la manera como ocurre la cooperación entre los pescadores artesanales, teniendo en cuenta el marco institucional e histórico descrito, así como diversos factores sociales, culturales y económicos de la pesca artesanal. Para esto se hizo, en primer lugar, una revisión histórica de las transformaciones que ha tenido la práctica y la organización de esta, prestando especial atención al efecto que la declaratoria de Puerto Libre (Guevara, 2007; Joya, 2001; Meisel-Roca, 2003) tuvo sobre la manera como la pesca artesanal había sido practicada. Y, en segundo lugar, se realizó un estudio de caso en una de las cooperativas de pescadores artesanales que dio cuenta de diversas formas de intercambio, reciprocidad y ayuda mutua, así como de las estrategias sociales de los pescadores en cuanto a la asociatividad cooperativista y frente a la práctica de la pesca en sí.

La cooperación se entendió como la acción complementaria orientada al logro del trabajo colectivo y que surge como resultado de la frecuente interacción de estrategias individuales. Esta puede ser fomentada tanto mediante la acción voluntaria de los individuos, como por la coevolución no planificada de múltiples estrategias individuales (Durston 2003, p. 158); y es un valor que sustenta los emprendimientos sociales solidarios, tales como cooperativas y asociaciones (Carranza, 2013). Es muy importante resaltar el aspecto no necesariamente voluntario de la cooperación, lo que quiere decir 
que para que esta exista no hay obligatoriedad en que los actores posean las mismas intenciones de trabajo colectivo. En el fondo, la investigación se interesó por la permanencia de las relaciones sociales que soportan el trabajo colectivo en las organizaciones cooperativistas.

Para ahondar en la comprensión de la permanencia de esas relaciones sociales, se evidenciaron otros aspectos en los intercambios y ayudas mutuas que existen entre los actores involucrados con la pesca artesanal, principalmente entre pescadores, compradores y directivos de la cooperativa. Estas relaciones se entendieron a partir del reconocimiento de que los intercambios evidenciados en la pesca artesanal pueden conjugar características del don y de las mercancías. Mientras estas últimas representan la existencia de un mercado, el cálculo del beneficio y la racionalidad, el don representa el poder, las obligaciones morales, el interés colectivo y la permanencia de las relaciones sociales antes y después de los intercambios (Gregory, 2009).

Tereucán-Angulo, Briceño-Olivera y GálvezNieto (2016) plantean que dicha dicotomía entre don y mercancía no corresponde a polos opuestos, "ya que en la práctica los intercambios pueden combinar elementos de mercado unido a formas y normas que son más aplicables a relaciones de reciprocidad" (p. 204). Además, porque puede haber transacciones del don con elementos individualistas y transacciones de mercancías con obligaciones mutuas. De ahí que, para no caer en esa división dicotómica, resultó útil comprender la equivalencia de la intercambiabilidad como un vector relevante en los intercambios, pues determina la permanencia de la deuda y, por lo tanto, de la solidaridad en las relaciones. Esto quiere decir que la obligación de devolver no siempre es totalmente equivalente y que puede prevalecer la asimetría entre el valor que se da y el que se recibe. Aquí entran en juego otros factores relevantes para las partes interactuantes como el contexto específico del intercambio, la relación social entre los participantes, las circunstancias económicas puntuales que originaron su no cumplimiento o el esfuerzo realizado para cumplir en parte con el compromiso.

En suma, esto da cuenta de que los individuos no siempre actúan en función de maximizar sus beneficios; muchas veces actúan en función de lo "socialmente correcto" y "aceptable" (Carranza, 2013). Igualmente, sus comportamientos pueden estar orientados a lograr objetivos como reputación, reciprocidad y conformidad con las normas sociales. Ello cobra relevancia en la pesca artesanal en donde, a pesar de que no siempre se da lo que se recibe, siguen existiendo intercambios. Desde un punto de vista práctico, se entiende que las devoluciones no siempre son iguales, ya que al equilibrarse los intercambios los compromisos morales dejarían de existir. Esto es un rasgo de algunas sociedades con economías multicéntricas, constituidas por al menos dos esferas con distintas transacciones: una más igualitaria de bienes de subsistencia y una más desigual de bienes de prestigio (Molina, 2004). En estas esferas operan conductas maximizadoras, ya sea del prestigio social o del beneficio económico, las cuales se dan en marcos institucionales históricamente determinados.

Por último, cabe anotar que los trabajos que se han hecho sobre los pescadores artesanales en San Andrés y Providencia (isla hermana de San Andrés) comprenden el estudio de las técnicas, los lugares de pesca y la relación con el ambiente (Buitrago 2004; Márquez 2005); la distribución espacial de los pescadores y las cantidades de captura (Agámez, 2004; Castro, Grandas y García, 2007); el estudio de la pesca en el marco de la Reserva de la Biosfera Seaflower (GómezLópez, 2012; Martínez, Hinojosa y Rozo 2009); y las dinámicas sociales y culturales relacionadas con la pesca (Pedraza 1984; Trujillo 1984). Por su parte, el estudio de las dinámicas cooperativas o del trabajo colectivo en torno a la pesca ha sido poco trabajado. En las tesis de pregrado de Zandra Pedraza (1984) y Adelaida Trujillo (1984), y más recientemente en la tesis doctoral de Ana Isabel Márquez 
(2014), podemos encontrar información sugerente respecto a la cooperación en la pesca de Providencia, pero probablemente el único trabajo que ha estudiado las dinámicas de cooperación en San Andrés ha sido el de Michael Rosberg (1980), el cual es revisado y retomado en este estudio.

\section{Aproximación metodológica}

La metodología adoptada en esta investigación fue de carácter cualitativo y etnográfico. En primer lugar, se hizo una revisión bibliográfica que permitiera contextualizar el marco histórico e institucional de la pesca artesanal. Posteriormente, tras haber consolidado una contextualización de las trayectorias históricas de la pesca artesanal en San Andrés, se realizó un estudio de caso en la cooperativa de pescadores artesanales Coopesbi. Fue un estudio de caso guiado por la teoría, por cuanto se enfocó en algunos aspectos teóricamente especificados de la realidad y se apartó de otros (Levy, 2008). Se escogió esta cooperativa debido a la mejor posibilidad de acceso frente a las demás. Su ubicación en pleno sector turístico y comercial hace que esté inmersa en el flujo continuo de turistas e isleños y que, por lo tanto, sus trabajadores estén más en contacto con quien no es de la cooperativa. De manera que esto suponía ciertas facilidades para mi llegada.

El trabajo de campo consistió en tres visitas a la isla de San Andrés en los meses de julio, octubre y noviembre de 2016, cada una de aproximadamente 15 días. La recolección de la información se hizo a partir de dos métodos. El principal de ellos fue la observación participante. Esta estuvo guiada por la reflexividad, la cual implicó que las observaciones registradas se interpretaran como construcciones de esa realidad (Guber, 2001). Esto significó que el entendimiento de los factores que forman la cooperación se hiciera a través de mi experiencia en campo, de una conceptualización previa y de un proceso continuo de cocreación con las nociones y las prácticas de los pescadores que daban cuenta de dicha cooperación.

El segundo método fue la entrevista etnográfica como complemento de la observación participante. En esta también fue fundamental el encuentro de las reflexividades, del investigador y de los entrevistados, en torno a la idea de bienestar. El rumbo de las entrevistas estuvo guiado por la "no directividad", la cual buscó el favorecimiento de la expresión de temáticas, términos y conceptos más espontáneos y significativos para el entrevistado. Como expone Rosana Guber (2001), esto se logró mediante una progresión de la entrevista desde los intereses más generales de la investigación hasta la focalización en las asociaciones libres del entrevistado. En total, se entrevistaron 26 personas, entre pescadores, compradores, líderes de las cooperativas y funcionarios públicos. Como tal no hubo un criterio de selección de los entrevistados. Las entrevistas fueron surgiendo a partir de los acercamientos personales del investigador, aprovechando relaciones construidas de confianza.

El trabajo de campo no estuvo exento de limitaciones. En primer lugar, el idioma significó una dificultad parcial. Si bien la mayoría pescadores hablan tanto creole como español, el manejo de estos idiomas varía según el contexto y tienen distinta función $y$ significancia. El creole es utilizado en los ámbitos más domésticos y cotidianos, mientras que el español es utilizado en contextos más formales y que denotan ciertas diferencias interculturales. En este sentido, la información obtenida estuvo mediada por el uso contextual del español o por la traducción que algunos pescadores hacían del creole $\mathrm{y}$, en segundo lugar, significó todo un reto poder generar empatía y confianza desde el principio. Inicialmente, algunos pescadores pensaron que el investigador iba de parte del gobierno, con lo cual surgieron ciertas expectativas por unos subsidios que se habían ofrecido recientemente; pero también se crearon sospechas debidas al cuestionamiento que los isleños tienen de la 
labor del poder central de Bogotá. Con el pasar de los días se logró aclarar el motivo de la visita, sin embargo, ello no significó la aprobación total de todos los pescadores. Algunos acogieron al investigador como un compañero más y le brindaron información sin la que hubiese sido imposible hacer este trabajo; pero también, hubo algunos cuantos que se resistieron determinantemente a dar cualquier tipo de información. En alguna de esas ocasiones un pescador veterano dijo: I dont give information to Santos $^{2}$.

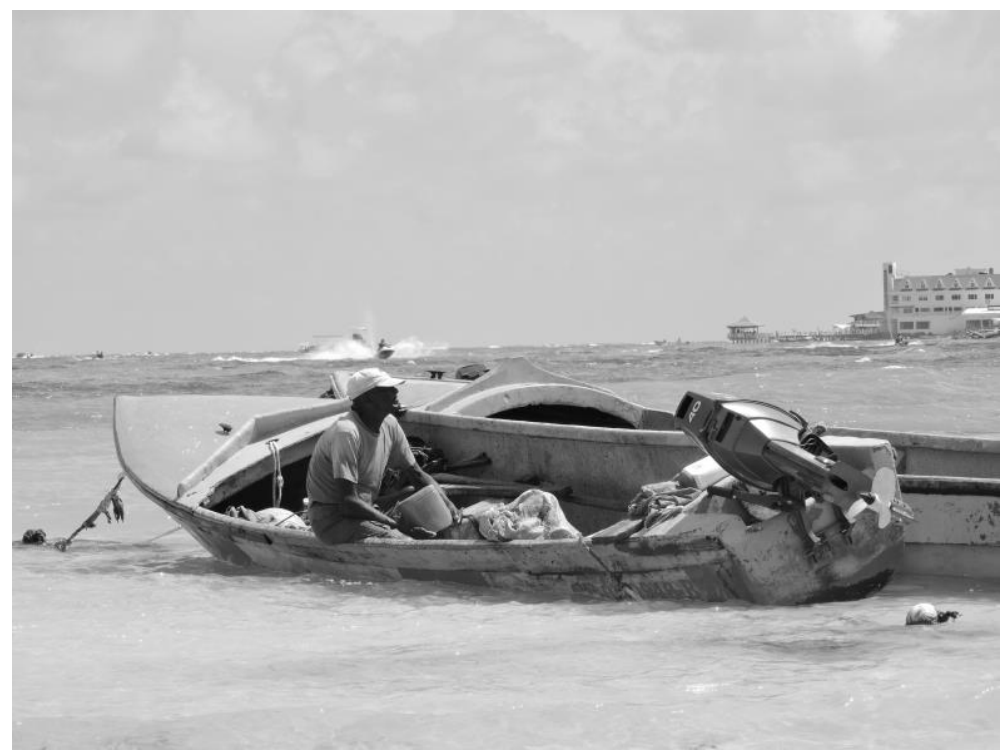

Figura 1. Marvin James, pescador y uno de los fundadores de la cooperativa Roos Carlos Barker. La foto fue tomada mientras desembarcaba en la playa de la cooperativa, hoy Coopesbi. ${ }^{3}$

\section{Transformaciones de la pesca artesanal de San Andrés}

\section{Orígenes}

La pesca en San Andrés y Providencia existe desde la presencia de los indios Misquito en estas islas, quienes las visitaban para ello y para cazar tortugas (Márquez, 2013). Después, con la llegada de europeos y esclavos, aparecieron las primeras configuraciones de lo que hoy es la pesca artesanal. Fueron esclavos africanos y sus descendientes quienes practicaron la pesca en medio del modelo de plantación esclavista que se había instaurado en Providencia. Estos primeros pescadores conformaron un grupo exclusivo dentro de la organización social, ya que su actividad implicaba una libertad

\footnotetext{
2 "No le voy a dar información a (Juan Manuel) Santos
} (Presidente de Colombia)". prohibida a otros esclavizados, en la medida en que podían salir al mar sin supervisión de nadie $\mathrm{y}$ tener acceso a alimentos que no eran del consumo general. Estas condiciones originaron un modo de vida caracterizado por el espíritu independiente y por el amor propio que se perpetua hasta hoy en día (Márquez, 2014).

Después de la emancipación y hasta la mitad del siglo XX, la pesca en el archipiélago fue de subsistencia, es decir, su producción fue destinada para la alimentación de los pescadores y sus familias. Era practicada por pocas personas; aquellas familias que no tenían un pescador en su familia y que se dedicaban a actividades de agricultura podían intercambiar sus productos con los pescadores para obtener pescado. Solo una pequeña cantidad del pescado

\footnotetext{
3 Todas las fotografías fueron tomadas por el autor del presente artículo.
} 
se vendía, pues era más común que las personas obtuvieran pescado de los pescadores que desembarcaban en las orillas, sin dinero a cambio (Pedraza 1984). Esto ocurría en un contexto económico en el que las dinámicas monetarias aún no eran protagónicas y en donde el flujo de bienes era principalmente propiciado por las redes de reciprocidad entre vecinos y familiares.

\section{Especialización}

Dichas dinámicas empezaron a hibridarse a mediados de siglo $\mathrm{XX}$, cuando se dieron varias trasformaciones en el modo de vida de la población isleña. Tras la declaratoria de Puerto Libre en 1953 y la construcción del aeropuerto en 1955, la población de San Andrés aumentó por la inmigración masiva de colombianos del continente y de algunos extranjeros siriolibaneses (Parsons, 1985). Ello significó un cambio categórico en sus estructuras económicas y culturales (Vollmer, 1997). Antes del Puerto Libre, las actividades predominantes eran la agricultura y la pesca, en una economía de autoabastecimiento, soportada por sistemas de trueque, cooperación y solidaridad. Con las emergentes condiciones de la economía del Puerto Libre, muchos isleños pasaron a ser partícipes de las nuevas actividades productivas de la isla, principalmente comerciales, turísticas y burocráticas.

Estos cambios influyeron para que, de manera paulatina, la pesca empezara a cambiar la manera como tradicionalmente fue practicada. El dinero empezó a tener una renovada importancia en diversos ámbitos de la economía local, incluyendo la pesca. Algunas especies marinas que nunca habían tenido valor comercial se volvieron especialmente demandadas por el mercado local (Márquez, 2013). Esto influyó en que algunos pescadores intentaran especializarse en la pesca como un trabajo de productividad monetaria. Los pescadores que se especializaron empezaron a pescar ya no semanalmente, sino diariamente y comenzaron a frecuentar lugares de pesca más lejanos, logrando una mejor captura (Márquez, 2014).

Michael Rosberg (1980) relata que dicho proceso fue muy evidente en un grupo nuclear de pescadores en North End, el sector que acogió el turismo y el comercio. Con el tiempo, aquel grupo de pescadores fundaron la primera cooperativa, en febrero de 1972, con unos objetivos claros:

Usar la cooperativa como una plataforma aprobada por el gobierno con la cual obtener recursos y distribuirlos de manera aceptable entre sus socios. Los primeros deseos fueron obtener una nueva embarcación con la Corporación Nacional de Turismo y un préstamo con la Caja Agraria para un refrigerador. Así, la cooperativa representó una oportunidad de vinculación con la estructura paternalista del gobierno (Rosberg, 1980: 125).

El surgimiento de dicha cooperativa fue posible gracias a un grupo nuclear de pescadores del sector conformado principalmente por miembros de la familia James, así como por algunos vecinos del sector. Estos pescadores lograron un fuerte sentido de cohesión en relación con los demás pescadores de la isla, debido a la costumbre generalizada que existía entre ellos de pescar para vender. Su posición en pleno sector turístico les permitía acceso directo a la incipiente demanda que representaba la llegada de hoteles, cuando el mercado de venta de pescado no tenía mayor competencia. También, el vivir cerca el uno del otro, así como los intercambios de dinero, equipamiento e información, permitió su consolidación como el primer grupo nuclear alrededor de la pesca especializada (Rosberg, 1980).

\section{Surgimiento de organizaciones cooperativistas}

Después de la fundación de Roos Carlos Barker, surgieron dos grupos similares en los sectores de San Luis y El Cove. Así se establecieron las tres principales cooperativas y puntos de 
desembarque de pescado, cuya importancia prevalece hasta hoy. Estas fueron las únicas en existir durante las tres décadas siguientes, situación que cambió hasta años recientes en que se empezó a evidenciar una proliferación de organizaciones. En el año 1999, según el estudio de James Clinton Pomare (1999), existían seis puntos de desembarque, pero solo funcionaban como cooperativas las mismas tres. Para el 2012 (GSAPSC, 2012) existían cinco organizaciones $\mathrm{y}$, según la última encuesta realizada por la Secretaría de Agricultura y Pesca (2014), existen hoy once organizaciones constituidas.

Esta propagación reciente puede ser explicada por dos momentos históricos. El primero fue a principios del 2000, cuando la declaratoria hecha por la Unesco del archipiélago como Reserva de Biosfera Seaflower produjo un cambio en la mirada sobre los recursos marinos del archipiélago, introduciendo discursos y políticas identificados con el desarrollo sostenible y el uso responsable de ellos, al tiempo que con la tecnificación de la pesca. En este contexto llegaron distintos programas de desarrollo, principalmente de Naciones Unidas, para fomentar una pesca artesanal sostenible. Aquellos pescadores que aún no pertenecían a ninguna organización conformaron nuevas organizaciones como requisito indispensable para acceder a los beneficios de los proyectos de desarrollo.

El segundo momento es el desatado tras el fallo de la Haya en el conflicto entre Colombia y Nicaragua que generó inestabilidad política en el archipiélago y un descontento generalizado de los isleños con el Gobierno colombiano. Los pescadores, principales protagonistas del suceso, denunciaron la pérdida de mar justamente en el área de mayor concentración de recursos pesqueros y criticaron el no haber sido tenidos en cuenta en el pleito, a pesar de ser quienes históricamente habían hecho uso de dicha porción de mar territorial. El gobierno de Juan Manuel Santos ofreció un subsidio de $\$ 1^{\prime} 800.000$ pesos por seis meses para cada uno de los pescadores artesanales, a manera de indemnización por los perjuicios causados a la comunidad de pescadores, pero también como una manera de calmar los ánimos inconformistas frente al gobierno. Si bien estos subsidios beneficiaron a la mayoría de pescadores, también significó que personas que no eran pescadores accedieran a los subsidios, ingresando como miembros a las organizaciones. Esto provocó la inscripción creciente de personas a las organizaciones y la fundación de nuevas.

\section{Estudio de caso}

La cooperativa de pescadores artesanales Coopesbi, más conocida como El Pescadero o The Fisherman Place, está ubicada en el sector Nord End y colinda con el hotel Decamerón Mary Land y el aeropuerto. Se encuentra al extremo de la playa más turística de la isla, Sprath Bight. Sus instalaciones están conformadas por un restaurante de interés turístico y por una construcción en donde están las oficinas de los directivos, un cuarto frío, un punto de venta de pescado al público y decenas de pequeños cuartos que sirven de bodegas para los pescadores asociados. En la playa, donde desembarcan los botes, está un pequeño cuarto al aire libre, en el que los pescadores pesan el pescado y lo venden a los compradores. 


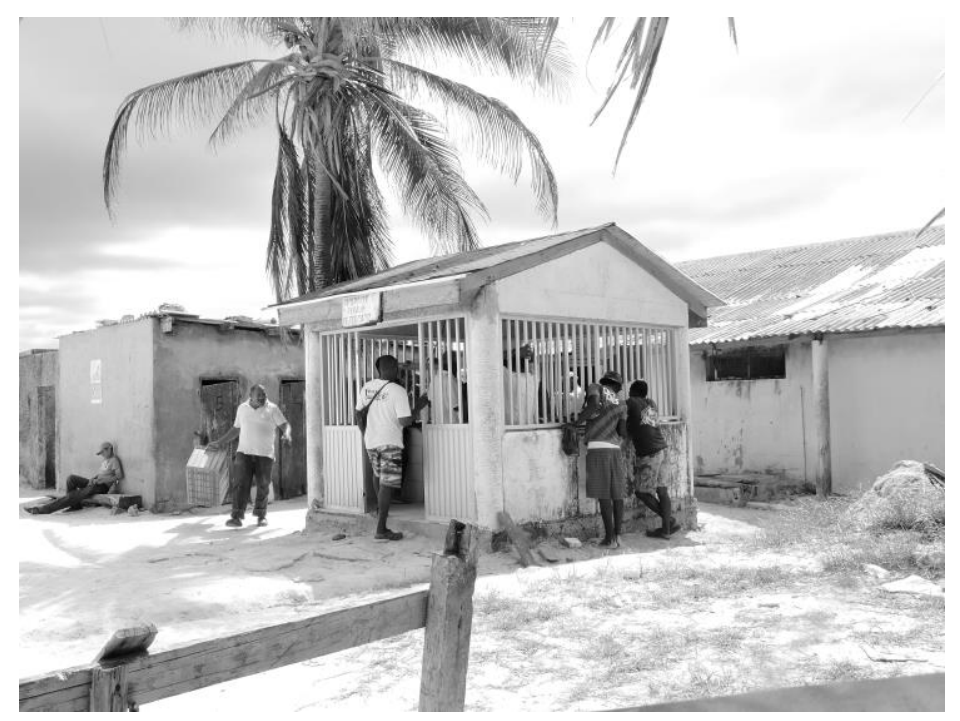

Figura 2. Vista a la cooperativa del lado de la playa. Se observa el cuarto de pesaje y venta de pescado.

Una de las razones que guio el trabajo de campo fue la de conocer por qué los pescadores trabajaban en la cooperativa, más allá de las razones que tienen que ver con la influencia que recientemente ha ejercido el Estado. Para ello indagué por los beneficios que ofrecía la cooperativa y el acceso a estos por parte de los pescadores.

En los estatutos de la cooperativa se estipula que su objetivo está dirigido a satisfacer las necesidades socioeconómicas de los asociados, contribuyendo a mejorar los niveles de vida. Dentro de las actividades que se estipulan para el beneficio de sus asociados están: compra y venta de pescado; captación de ahorros y la adjudicación de diversas modalidades de crédito; e importación, comercialización y financiamiento de vehículos náuticos, motores y repuestos. Además de estos beneficios, existen otros a los que los pescadores pueden acceder que no se mencionan en los estatutos, tales como descuentos en los productos del restaurante y acceso y uso de las instalaciones de la cooperativa para guardar implementos de pesca o almacenar pescado. También existe el derecho a participar, con voz y voto, en la asamblea general que se realiza anualmente, en la que se elige la junta directiva de la cooperativa. Se supone que los asociados pueden acceder a todos estos beneficios siempre y cuando estén activos, lo cual está determinado por el cumplimiento de sus aportes mensuales de $\$ 20.000$ pesos colombianos (\$6 dólares).

Ahora bien, a pesar de que muchos pescadores no cumplen con sus aportes, estos pueden acceder a la mayoría de beneficios de la cooperativa. De los 62 asociados, únicamente 20 pagan sus aportes, pero la mayoría hace uso de las instalaciones, venden el pescado a la cooperativa, obtienen alimentos del restaurante a precios bajos y, en algunos casos, hacen uso de las embarcaciones de la cooperativa. Realmente aquellos derechos a los que solamente pueden acceder quienes están asociados y cumplen con los aportes son los relacionados con los préstamos de dinero, facilitación de embarcaciones y acceso a programas del Gobierno. De igual manera, quienes hacen el aporte tienen el derecho al voto en la asamblea general para elegir la junta directiva. En medio de todo, llama la atención que de los 20 que cumplen con sus aportes, al menos la mitad tiene responsabilidades administrativas con la cooperativa. Los cinco integrantes de la junta directiva, así como los cinco suplentes, estaban todos al día con sus aportes. 
Por otro lado, hay algunos pescadores que sin estar asociados también tienen acceso a ciertos beneficios por medio de algún compañero que sí esté asociado. Arnold Howard, pescador asociado, mencionaba algunos de esos beneficios:

A los demás (no asociados) les dan el privilegio de bañarse, usar la ducha, parquear su lancha, usar el baño y fritar un pescado. Vienen cansados y con hambre y le piden al gerente o cualquier socio "frítame este pescado". Y sí, uno como pescador los ayuda. $\mathrm{Y}$ pues como compañeros de pesca. Los socios tienen el privilegio de fritar un pescado, de pedir un poquito de arroz, pero el independiente no. Entonces uno le dice "tráeme el pescado, compañero de pesca, yo lo llevo y lo frito", y le doy su plato de comida como si fuera mío (Entrevista, septiembre de 2016).

Así pues, muchos de los beneficios que ofrece la cooperativa son extensivos a todos los pescadores que trabajan en ella, independientemente de su pertenencia formal. Eso es posible, en parte, debido a la ausencia de mecanismos de restricción para que los pescadores hagan uso del espacio de la cooperativa, aparquen sus lanchas y utilicen sus instalaciones. Sin embargo, esto no significa que cualquier pescador pueda trabajar en la cooperativa, ya que depende de la red de relaciones de cada persona, en donde entran a jugar factores como el parentesco, la amistad y la reputación.

Entonces, la asociatividad en la cooperativa dista de darse de manera igualitaria. Dependiendo de los intereses de cada persona, así como de su capital social, establecen distintos tipos de vínculos con la cooperativa: no asociado, asociado no aportante y asociado aportante. Lo que vale la pena recalcar acá es que en las dos primeras categorías se ubican quienes salen a pescar frecuentemente, mientras que en la última categoría se encuentran quienes por su edad u otras razones han dejado de pescar para dedicarse a labores administrativas. Entonces, el funcionamiento de la cooperativa no está determinado estrictamente por sus estatutos y normas formales, ya que sus beneficios no solo son aprovechados por los asociados activos, sino también por los asociados inactivos, y aquellos que sí cumplen con sus aportes son quienes tienen alguna relación o interés con la administración de la cooperativa.

\section{Organización y roles en la cooperativa}

Para conocer el contexto en el que los pescadores establecen sus relaciones sociales y laborales, se presentan los roles más representativos que se pueden encontrar en el ámbito de la cooperativa. Igualmente, esto servirá para poner de relieve ciertos valores y actitudes propios de la práctica de la pesca que tienen efectos en la manera como se da la cooperación en la pesca artesanal de San Andrés.

Es importante adelantar que uno de los valores que más relevancia adquirieron en el análisis fue el de la "reputación". El antropólogo Peter Wilson (2004) notó esto en un estudio que hizo sobre la sociedad raizal de Providencia. Para Peter Wilson la reputación de un isleño es "la muestra de respeto de otra gente por él" y además significa un elemento de preocupación de todo hombre por mantener su buen nombre. En los pescadores esto se ve representado en su valentía para salir a pescar mar adentro, así como en la acumulación de conocimiento, experiencia e historias para contar. La reputación influye en la vida social del pescador en la medida en que le permite desarrollar su propia identidad dentro del grupo, procurando el respeto de las demás personas hacia él. Ese es un elemento determinante para la relación entre pescadores, ya que determina las preferencias para trabajar entre sí. Por ejemplo, un pescador que tenga reputación de ser mal navegante no va a conseguir mucha gente que quiera ir con él.

Adicionalmente, estar mar adentro con una persona por varias horas o incluso días puede resultar tormentoso si no se tiene una buena 
relación. Sin lugar a dudas, no resulta fácil compartir un espacio reducido como el de una lancha en condiciones poco cómodas, con cansancio físico producto de jornadas extensas de trabajo, con acceso limitado a agua potable y alimento, y en movimiento permanente. El pescador que logra lidiar con estas condiciones, goza de buena reputación. Ello es muestra de sus habilidades adquiridas, lo que a su vez le confiere prestigio (Márquez, 2014, pp. 113-114).

\section{Directivos}

Los directivos suelen haber sido pescadores antes de dedicarse a la administración de la cooperativa. Son individuos que tienen bastante antigüedad en la cooperativa, con edades entre los 45 y los 60 años, y que tienen cierta afinidad con los miembros fundadores. Sus funciones están relacionadas con tareas administrativas, tales como el manejo administrativo del restaurante, la vigilancia en la compra y venta de pescado, y los trámites para acceder a los recursos provenientes del gobierno. Asimismo, los directivos son los encargados de representar al grupo de pescadores de la cooperativa ante las instancias regionales y nacionales para acceder a programas de beneficio social y económico.

La junta directiva de la cooperativa está conformada por cinco principales: presidente, vicepresidente, tesorero, secretario y gerente. Esta es elegida cada año en una asamblea general, en donde cada asociado que esté al día con sus aportes tiene el derecho a votar. Como se dijo, solo veinte asociados cumplen con sus aportes, de tal manera que la junta directiva, conformada por diez personas (incluyendo suplentes), es elegida apenas por dichos veinte. Esto evidencia que la mayoría de los pescadores están muy desprendidos de los asuntos administrativos y prefieren dejárselo a los directivos y a quienes aspiran a serlo. Y, además, que la junta directiva se está rotando entre esas veinte personas, lo cual no se da de manera totalmente igualitaria, sino que depende de la reputación de cada uno para hacerse elegir por la junta directiva.

Por otro lado, los directivos tienen una popularidad ambigua, pues, si bien son personas respetadas por sus lazos de amistad y parentesco con los demás pescadores, así como por su edad y experiencia, suelen ser percibidos por algunos pescadores como corruptos, mentirosos $u$ oportunistas. Es común escuchar a los pescadores decir que los directivos no han hecho más que "quebrar a la cooperativa" y que, a pesar de que todos saben, nadie dice nada. Un pescador decía que quien está al día en sus aportes es porque le interesa la administración de la cooperativa y porque tiene interés de ocupar algún cargo directivo:

En esta cooperativa los gerentes siempre se han robado la plata, como ellos ponen su aporte $y$ nunca han conseguido beneficio, entonces de pronto usted es socio y el otro es asociado, lo eligen como gerente y se lleva toda la plata. Pero como el otro no consigue nada, entonces después lo eligen como gerente para que se robe toda la plata. Y así es como se va la plata del aporte. Y así se va el uno contra el otro. Pero eso es en general de los pescadores (Castilo Bryan, entrevista, octubre de 2016).

La confianza de los pescadores con los directivos está sujeta a la estabilidad económica en la cooperativa. La historia reciente de la cooperativa está marcada por desfalcos y chismes sobre presuntas irregularidades de los administrativos. En la actualidad, la confianza que se tiene con los directivos es muy baja y, en definitiva, los pescadores no ven beneficios en cumplir con sus aportes para ser asociados activos. Por su parte, los directivos atribuyen la falta de asociación formal a la ausencia de espíritu cooperativista y emprendedor de los pescadores y al bajo grado de educación. Uno de ellos me decía: 
Yo creo que hace falta un poco más de capacitación educativa, falta más educación a los asociados para que se les eduque en qué significa cooperativa, porque después de que el asociado conozca sus deberes se puede hacer crecer mucho más la cooperativa y eso es lo que le hace falta a muchos que todavía no han tenido esa apropiación y ese conocimiento de lo que es la cooperativa (César de Alba Barker, entrevista, octubre de 2016).

\section{Capitanes y acompañantes}

Entre quienes son pescadores se pueden distinguir dos roles: el de capitán y el de acompañante. La mayoría de faenas están integradas por dos personas, cada una en condición de alguno de los dos roles. La diferencia entre estos dos roles radica en la toma de decisiones, siendo el capitán quien comanda. El capitán es aquella persona que tiene suficiente experiencia y conocimiento para navegar largas distancias, conocer los lugares de pesca y estar al tanto de que ninguno de los insumos falte (comida, hielo, carnada, vela, gasolina). Además, por lo general el capitán es el responsable de la embarcación, ya sea porque es dueño o por haberla conseguido arrendada de otra persona. Por su parte, las funciones del acompañante se diferencian por el grado de responsabilidad que tiene con la embarcación y la navegación, y porque debe acatar las órdenes que le dé el capitán, sin llegar a ser un acatamiento sumiso.

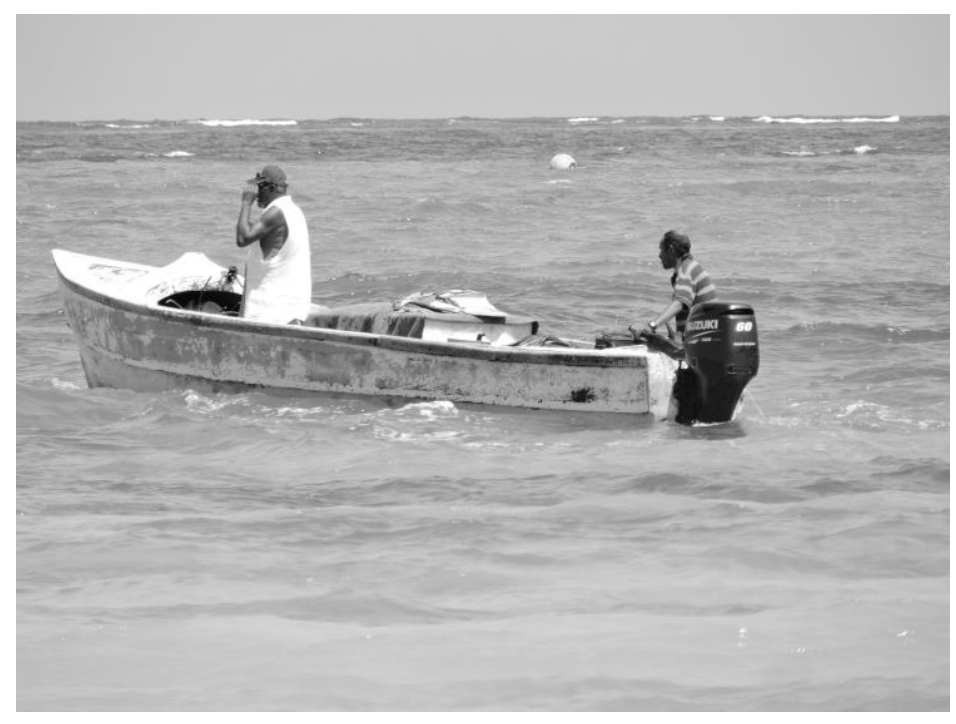

Figura 3. Capitán (al mando del motor) y acompañante saliendo de faena.

La repartición de las ganancias es otro aspecto que diferencia el rol de capitán del de acompañante. Es el capitán quien, al regresar a tierra con el producto capturado, se encarga de administrar la venta de pescado y posteriormente la repartición del dinero, entre él, el acompañante y la embarcación. No obstante, dicha repartición es igualitaria y, en teoría, nadie tendría por qué ganar más que el otro. Al respecto un pescador afirmaba:
Mira, el pescador no tiene rango, pero uno de los dos tiene que dirigir la lancha hasta el sitio de pesca, que es el capitán. Los dos hacemos lo mismo. Lo que yo hago, lo hace él y él como capitán a veces hace mejor que el compañero, por la experiencia. Pero los dos hacemos casi lo mismo, los dos pescamos, los dos limpiamos el pescado. Pero claro, el capitán es el que cobra la plata y la reparte, 
eso sí, en partes iguales (Arnold Howard, entrevista, septiembre de 2016).

Este testimonio es muestra de que la división de roles no está motivada por la ganancia económica, sino por una condición inherente a la pesca y la navegación en la que es necesario que la toma de decisiones recaiga, de manera proporcional, en una sola persona. En suma, la diferencia entre estos dos roles radica en el grado de responsabilidad con la faena y en la reputación como navegante y pescador. Los capitanes suelen tener ciertas habilidades sociales y psicológicas, tales como la capacidad para tomar decisiones en situaciones de riesgo y de simpatizar con los demás pescadores en condiciones poco confortables. La reputación de quien es capitán es muestra de estas habilidades e influye en el respeto que los demás tienen por él, lo cual es fundamental para la deseabilidad de trabajo en equipo y el acatamiento de órdenes. En los acompañantes, la experiencia, el conocimiento y la reputación no dejan de ser atributos importantes, pero estos se dan en relación a la reputación del capitán.

En ocasiones, cuando hay inconformidades entre capitán y acompañante, es posible que busquen otros compañeros de pesca. Lo mismo ocurre cuando por motivos de salud o fuerza mayor alguno de los dos no puede salir. Esto es posible gracias a la gran movilidad que existe entre los pescadores, en la que cada pescador dispone de una red de relaciones que le permite ejercer esta actividad y en la que entra a jugar la reputación de cada quien.

\section{Compradores}

Los compradores son individuos externos a la cooperativa que han establecido ciertas relaciones de confianza con los pescadores. La mayoría del tiempo hay más demanda que oferta, es decir, hay más compradores pendientes de comprar pescado que pescadores buscando venderlo. Esto hace que los compradores se interesen en establecer relaciones duraderas con los pescadores, retroalimentadas con préstamos y ayudas económicas. Generalmente, los pescadores tienen sus compradores fijos con quienes han establecido ciertos acuerdos tácitos, basados en relaciones de confianza y en intercambios. En ocasiones, los compradores ponen el crédito inicial para las faenas de aquellos pescadores con los que tienen relaciones de confianza. Al respecto, un comprador afirmaba:

\begin{abstract}
Yo les compro a todos los pescadores, pero también tengo personas fijas que me venden y que salen por una semana, cinco días, seis días, ocho días. También les hago préstamos. Por ejemplo, si van una semana yo les doy un millón de pesos y de todo el pescado que traen, yo le saco la cuenta de más o menos el resultado que queda de la cantidad del pescado; resto los gastos que yo puse; y les doy la plata que les toca (Eduardo Bernard Bowdem, entrevista septiembre de 2016).
\end{abstract}

Así, algunos compradores establecen relaciones de intercambio con los pescadores, donde los primeros proveen los recursos necesarios para la realización de las faenas, tales como carnada, combustible o dinero, y los segundos retribuyen con pescado al regresar de sus faenas. De manera que, entre pescadores y compradores existen relaciones de expectativa mutua en las cuales los compradores esperan la fidelidad de los pescadores, a cambio de préstamos cuando el pescador lo requiere. Esto representa una relación complementaria, en donde los pescadores tienen la ventaja de una gran demanda del producto y los compradores tienen mayor estabilidad monetaria que la que tienen los pescadores. Adicionalmente, esta relación permite que el riesgo no recaiga únicamente en los pescadores. El pescador siempre enfrenta el riesgo de no conseguir suficiente pescado, de las fallas técnicas que pueda presentar la faena e, incluso, de naufragar. Por ende, esas inversiones que algunos compradores hacen con algunos pescadores permite que el riesgo sea compartido. 
Esto se evidencia por el hecho de que el retorno que los pescadores le dan a los compradores solo se hace al final de que han saldado todas sus cuentas; es decir, de que han vendido el pescado y repartido las ganancias. La obligación de devolver no siempre es totalmente equivalente, pues entran en juego otros factores relevantes para las partes interactuantes como el contexto específico del intercambio, la relación social entre los participantes y las razones por las cuales se cumplió total o parcialmente el compromiso.

\section{Manahuares}

Por último, los ayudantes o "manahuares" son individuos que siempre están en tierra y que fueron pescadores, pero que por algún motivo dejaron de ir a las faenas. Les dicen así a manera de símil con un ave de playa que caza peces en las orillas y que suele estar atento a los desperdicios que botan los pescadores. Los manahuares están pendientes de las lanchas que salen y llegan, ayudándolas a zarpar y a desembarcar. Esta labor es vista más como una colaboración, por la cual obtienen uno o dos pescados de cada embarcación que ayudan. En la cooperativa había unos cinco manahuares con distintos grados de dedicación. Un manahuar de tiempo completo puede obtener en promedio unos ocho pescados diarios, que suelen ser "bonito" o "jurel". En dinero, esto representa unos $\$ 40.000$ pesos (\$12 dólares) diarios, sin embargo, el pescado que obtienen no solo lo intercambian por dinero, sino por otros alimentos o artículos. De igual manera, en los manahuares también existe la costumbre de dar pescado, como un "don", a allegados u otros pescadores.

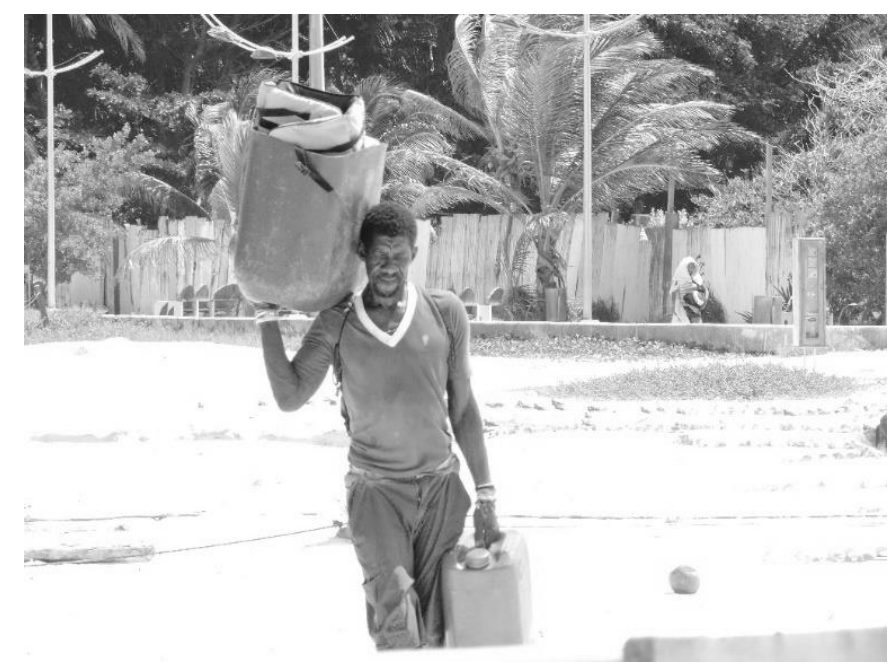

Figura 4. Castilo Bryan es uno de los manahuares de la cooperativa Coopesbi. La foto fue tomada mientras ayudaba a descargar insumos de un bote recién llegado de faena.

Esta labor de manahuar está muy relacionada con las actitudes de reciprocidad que existen entre los pescadores, pues, a pesar de ser una labor gracias a la cual consiguen su sustento, es vista más como una colaboración mutua en la que se intercambia ayuda con pescado y en la que no se cuantifica el valor monetario del pescado que se da. Acá es evidente la articulación de las lógicas que se dan en la pesca artesanal, en donde las dinámicas de reciprocidad ocurren en medio de la existencia de un mercado especializado.

\section{Cooperación en la pesca artesanal}

Muchas de las dinámicas encontradas en el estudio de caso coincidieron con un rasgo de la 
cultura isleña de San Andrés descrito por el antropólogo Michael Rosberg (1980), a la cual llamó "estrategia de generosidad generalizada". Esta procura preservar las relaciones sociales con las demás personas en un contexto como el sanandresano, marcado por la inestabilidad económica y ambiental. Dicha ética de la generosidad se basa en dar sin recibir nada a cambio de manera inmediata, pues no se sabe cuándo se va a necesitar de la ayuda de esa otra persona. Esto ha sido muy importante para la práctica de la pesca, cuyo rasgo principal es su inestabilidad, tanto por la dependencia del recurso común de la pesca, cuya disponibilidad varía en el tiempo, como por las difíciles condiciones que representa el mar.

Rosberg propuso un modelo de decisión que da cuenta de las estrategias que los pescadores artesanales de San Andrés utilizan en contextos de cooperación. Afirmó que estos buscan aprovechar las oportunidades económicas inmediatas, siempre y cuando ello no vaya en detrimento de los vínculos sociales de larga duración. Esto tendría que ver con el hecho de que el permanente clima de inseguridad ambiental, política y económica a lo largo de la historia de San Andrés ha hecho que los isleños generen "estrategias de generosidad generalizada", por medio de las cuales pueden recurrir a su red de relaciones cuando vienen los tiempos difíciles.

Así pues, actitudes como la de regalar pescado son bastante significativas al respecto. En promedio, los pescadores regalan a otros pescadores u otras personas el $20 \%$ de lo que capturan (Olmos, 2016). Esto corresponde a dinámicas ajenas al mercado, pues son resultado de los sistemas de reciprocidad vigentes en la isla. No se cuantifica el valor monetario del pescado que se regala, en cambio, se da con motivo de establecer relaciones recíprocas entre pares, de ser caritativo con quien lo necesita o de generar un sentido de asociatividad comunitaria. Este tipo de dinámicas, sumadas a aquellas que dependen de la pesca como cadena productiva vinculada a un mercado especializado, dio pie para entender que la cooperación se da en medio de la coexistencia de dos circuitos: uno determinado por la transacción de productos y ganancias monetarias, y otro influenciado por relaciones asimétricas de poder y prestigio. La coexistencia entre esos circuitos se evidencia en las relaciones que todos los roles establecen entre sí. Por ejemplo, la percepción que existe en torno a los directivos como corruptos puede obedecer a que ellos operan en un circuito predominantemente mercantil. Sus labores, tales como la compra y venta de pescado y la administración de los recursos de la cooperativa, responden a marcos legales y contables. Sin embargo, de manera paralela, la rotación de los puestos directivos está mediado por factores como la capacidad de las personas para dirigir, liderar y administrar, y, en suma, su reputación. Entonces, la rotación de cargos administrativos funciona con principios recíprocos, estableciéndose una distribución rotativa en el manejo de recursos monetarios.

Por su parte, en la relación entre compradores y pescadores también está presente el doble circuito de mercancía y de dones. Este último permite que el riesgo no recaiga únicamente en el pescador, sino que los mismos compradores también asuman las condiciones que implica vivir de una actividad incierta y riesgosa como es la pesca artesanal. En cuanto a la relación entre capitán y acompañante, esto se evidencia en el hecho de que la repartición de las ganancias se da de manera igualitaria, a pesar de que son dos rangos con asimetría de poder. Esto quiere decir que sí hay equivalencia en cuanto a la mercancía, pero no en cuanto al prestigio. El capitán es quien toma las decisiones y su rol es soportado por la reputación que tiene y el respeto que el acompañante le debe tener.

En suma, la coexistencia de lógicas mercantiles con lógicas de reciprocidad moral posibilita que la pesca artesanal sea una actividad a partir de la cual los pescadores pueden conseguir su sustento, al tiempo que les permite participar de una red de relaciones indispensable para la práctica de la pesca. Entonces, el intercambio de 
mercancías establece relaciones cuantitativas entre objetos transados, mientras que el intercambio de dones establece relaciones cualitativas entre sujetos involucrados (Gregory, 2009). Aun así, se trata de una dualidad que no es opuesta sino complementaria. Mientras las transacciones económicas, tales como la repartición de ganancias que deja la faena, se retroalimentan con un fuerte sentido de trabajo colectivo, el prestigio individual del pescador se ve reforzado por el hecho de que es rentable que los demás trabajen con él.

Estas normas subyacentes a los intercambios y ayudas mutuas que se dan en la pesca artesanal son socializadas continuamente en espacios como el juego de dominó que, justamente, convoca en horas de la tarde tanto a pescadores como directivos, compradores y manahuares. Allí se comparten y discuten situaciones del trabajo cotidiano que establecen lo socialmente correcto. Muchas veces estas discusiones acaban en confrontaciones declaradas debido a que siempre hay inconformidades, ya sea por algo sucedido en las faenas de pesca, por algún préstamo no devuelto o por malentendidos en el mismo juego de dominó. Es como si este juego le diese trámite al ciclo de dar, recibir y devolver, poniendo en evidencia las equivalencias asimétricas entre las relaciones y la reputación de los individuos.

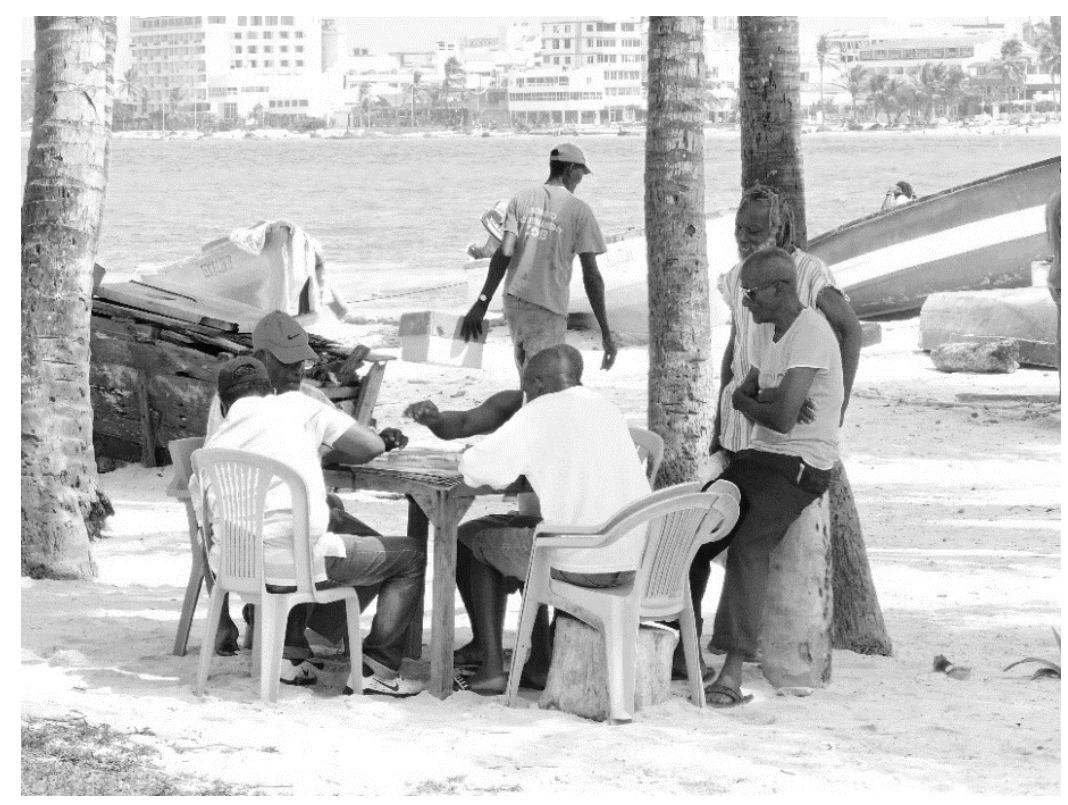

Figura 5. Pescadores y amigos jugando dominó en la playa de la cooperativa.

\section{Conclusiones}

Con este trabajo se buscó presentar una visión renovada de la pesca artesanal en San Andrés, estudiando algunos elementos que dan cuenta de la cooperación. Se partió de la premisa de que la cooperación tiene orígenes sociales, culturales, históricos e institucionales que pueden ser estudiados para comprender cómo es la cooperación en la actualidad. El estudio de dichos aspectos se hizo tanto en la práctica de la pesca en sí, como en los procesos organizativos en torno a ella. Así pues, se encontró que la cooperación ha surgido a partir de dos eventualidades: la primera es aquella por la cual la pesca se ha especializado e institucionalizado con base en un modelo cooperativista, en donde las organizaciones agrupan a los pescadores y sirven de intermediadoras entre estos y el nivel estatal; y la segunda tiene que ver con las redes de apoyo habituales entre los mismos 
pescadores, que posibilitan ejercer la pesca de manera conjunta.

Estos procesos han surgido en respuesta a las circunstancias socioeconómicas de la isla, en la medida en que las condiciones del mercado han influido en la especialización de la pesca artesanal como un trabajo que permite la subsistencia de los pescadores. En esta investigación se rastrearon dichos procesos desde mediados del siglo XX, cuando se dio la declaratoria de Puerto libre en San Andrés, que significó la implementación de un modelo económico basado en el comercio y el turismo, lo que causó el aumento de la población y la monetarización de la economía. En este contexto, la pesca dejó de ser una actividad exclusiva para el autoconsumo e intercambio de productos y empezó a especializarse como un trabajo que permite ingresos monetarios. Además, las agencias gubernamentales empezaron a promover la tecnificación y la organización de la pesca, motivando la creación de organizaciones cooperativas como plataformas adecuadas para la transferencia de recursos e incentivos a los pescadores.

La fundación de la primera cooperativa, Roos Carlos Barker, da cuenta de las nacientes dinámicas cooperativas de la pesca especializada. Esta cooperativa fue fundada por un grupo nuclear de pescadores con vínculos de parentesco y amistad, alrededor del cual se dio la asociatividad formal. La asociación a la cooperativa estaba motivada por reducir los costos de producción por medio del acceso a diversos tipos de bienes (Rosberg, 1980). No obstante, la participación en la cooperativa, como la obtención de beneficios, no estaban sujetas totalmente a la pertenencia formal. Más bien, la cooperativa servía como un espacio en el que los pescadores podían desarrollar su actividad, estableciendo distintos grados de asociación.

En el estudio de caso, mostré que en la actualidad se mantiene una situación muy parecida. En Coopesbi, antes Roos Carlos
Barker, sigue existiendo una dinámica donde cada quién establece distintos grados de asociación según sus intereses y capital social. Quienes sí cumplen con sus aportes tienen intereses o vínculos evidentes con las funciones administrativas de la cooperativa y su legitimidad en los cargos administrativos sigue estando sustentada por la antiguiedad y afinidad con los miembros fundadores. Por su parte, al resto de pescadores les basta con tener una asociación parcial a la cooperativa, que les permite seguir trabajando en el espacio de la cooperativa y acceder a ciertos beneficios sin necesidad de pagar los aportes mensuales requeridos para ser miembros activos.

En suma, las transformaciones de la pesca artesanal dan cuenta de la manera como los pescadores se adaptaron a las condiciones que generó el Puerto Libre. En ese sentido, pueden ser vistas como adaptaciones que han sabido hibridar los conocimientos tradicionales con la participación en la economía de mercado. Justamente este estudio pretendió aportar al entendimiento de que la cooperación en los pescadores ocurre de manera híbrida, pues entran en juego las pautas organizativas de los modelos cooperativistas, así como las normas informales y los valores que han acompañado la práctica de la pesca artesanal. El reconocimiento de esta dualidad puede ser una oportunidad para migrar de la concepción formalista a una que reconozca la identidad del pescador como un factor constituyente de la organización en torno a la pesca artesanal.

Entre otras cosas, esto implica reconocer que los pescadores no siempre actúan en función de maximizar sus beneficios económicos; muchas veces actúan en función de lo socialmente correcto y aceptable, que tiene que ver con factores como la reputación, la reciprocidad y la conformidad con las normas sociales. 


\section{Agradecimientos}

Este trabajo fue posible gracias a la beca de Fomento a la Investigación 2016 del Instituto Colombiano de Antropología (ICANH), entidad a la cual le debo mis agradecimientos.

\section{Referencias}

Agámez, E. B. (2004). Pesca artesanal y sus atributos espaciales en San Andrés Isla, Colombia. Cuadernos del Caribe, 3 (5), 21-28. Recuperado de https://revistas.unal.edu.co/index.php/ccar ibe/article/viewFile/41754/43445

Aguilera-Díaz, M. M. (2010). Geografía económica del Archipiélago de San Andrés, Providencia y Santa Catalina. Documentos de Trabajo Sobre Economía Regional y Urbana, (133). Recuperado de http://www.banrep.gov.co/sites/default/fil es/publicaciones/archivos/DTSER133.pdf

Buitrago, D. (2004). La pesquería en Providencia y Santa Catalina, islas del Caribe Occidental. Estrategias de aprovechamiento de recursos marinos relacionadas con el palangre vertical. Trabajo de pregrado para optar al título de Biólogo Marino, Fundación Universidad de Bogotá Jorge Tadeo Lozano, Bogotá. Recuperado de http://expeditiorepositorio.utadeo.edu.co/ bitstream/handle/20.500.12010/1371/T69 7.pdf? sequence $=1 \&$ is Allowed $=y$

Carranza, C. (2013). Economía de la Reciprocidad: Una aproximación a la Economía Social y Solidaria desde el concepto del don. Otra Economía, 7(12), 14-25. Recuperado de http://www.revistas.unisinos.br/index.php /otraeconomia/article/view/3224
Castro, E., Grandas, Y. y García, C. (2007). Conocimiento pesquero tradicional: Aplicación del Análisis de Consenso Cultural para la evaluación y el manejo de la pesquería artesanal de la Isla de San Andrés, Colombia. Proc Gulf Carib Fish Inst 58, 117-122. Recuperado de https://www.researchgate.net/publication/ 312164491_Conocimiento_Pesquero_Tra dicional_Aplicacion_del_Analisis_de_Co nsenso_Cultural_para_la_Evaluacion_y_e 1_Manejo_de_la_Pesqueria_Artesanal_de 1_la_Isla_de_San_Andres_Colombia_Tra ditional_Fishing_Knowledge

Durston, J. (2003). Capital social: parte del problema, parte de la solución, su papel en la persistencia y en la superación de la pobreza en América Latina y el Caribe. En R. Atria (Ed.) Capital social y reducción de la pobreza en América Latina y el Caribe: en busca de un nuevo paradigma. United Nations Publications. Recuperado de

https://www.cepal.org/prensa/noticias/co municados/3/7903/Durstonvale.pdf

Gregory, C. (2009). Whatever happened to economic anthropology? The Australian Journal of Anthropology, 20(3), 285-300.

Gobernación de San Andrés Providencia y Santa Catalina. (2012). Plan de Desarrollo 2012-2015. Para tejer un mundo más humano y seguro. San Andrés: Departamento Administrativo de Planeación.

Gómez-López, D. I. (Ed.). (2012). Atlas de la Reserva de la Biósfera Seaflower: archipiélago de San Andrés, Providencia y Santa Catalina. INVEMAR. Recuperado de

http://www.invemar.org.co/redcostera1/in vemar/docs/10447AtlasSAISeaflower.pdf

Guber, R. (2001). La etnografía: método, campo y reflexividad 11. Editorial Norma. 
Guevara, N. (2007). San Andrés Isla, memorias de la colombianización y reparaciones. En M. Lux. y M. Laurent. (Eds.) Afroreparaciones: memorias de la esclavitud y justicia reparativa para negros, afrocolombianos y raizales. Bogotá: Universidad Nacional de Colombia, Centro de Estudios Sociales (CES). Recuperado de http://www.bdigital.unal.edu.co/1237/10/ 09CAPI08.pdf

Joya, C. A. (2011). En el trasfondo de la ‘colombianización': el archipiélago de San Andrés visto por funcionarios del Estado colombiano (1888-1924). Sociedad y Economía (2), 73-94. Recuperado de https://www.researchgate.net/publication/ 277095637_En_el_trasfondo_de_la_'colo mbianizacion'_el_archipielago_de_San_A ndres_visto_por_funcionarios_del_Estado _colombiano_1888-1924

Levy, J. S. (2008). Case studies: Types, designs, and logics of inference. Conflict management and peace science, 25(1), 118.

Márquez, A. I. (2005). Los pescadores artesanales de Old Providence Island: una aproximación al estudio de las relaciones seres humanos-medio ambiente. Tesis de pregrado para optar al título de Antropóloga, Universidad Nacional de Colombia, Bogotá.

Márquez, A. I. (2013). Fi wi sea / Nuestro mar / Our sea. Historias y memorias del mar isleño raizal. Bogotá: Instituto Colombiano de Antropología e Historia (ICANH).

Márquez, A. I. (2014). Povos dos recifes: reconfigurações na apropriação social de ecossistemas marinhos e litorâneos em duas comunidades do Caribe. Tesis doctoral, Instituto de Ciências Humanas E Sociais, UFRRJ, Rio de Janeiro.
Martínez, A. S., Hinojosa, S. y Rozo, O. S. (2009). Proceso y avance hacia la sostenibilidad ambiental: la reserva de biosfera Seaflower, en el caribe colombiano. Cuadernos del Caribe, 7(13), 7-23. Recuperado de http://bdigital.unal.edu.co/38475/1/41323 -186484-1-PB.pdf

Meisel-Roca, A. (2003). La continentalización de la isla de San Andrés, Colombia: Panyas, raizales y turismo, 19532003. Documentos de Trabajo Sobre Economía Regional y Urbana 37. Recuperado http://www.banrep.gov.co/docum/Lectura _finanzas/pdf/DTSER37-SanAndres.pdf

Molina, J. L. (2004). Manual de antropología económica. Bogotá: UAB. Recuperado de https://antroporecursos.files.wordpress.co m/2009/03/molina-j-1-2004-manual-deantropologia-economica.pdf

Olmos, A. (2016). You never know when you will need a friend. Cooperación en los pescadores artesanales de San Andrés. Trabajo de pregrado para optar al título de antropólogo. Universidad Nacional de Colombia. Facultad de Ciencias Humanas y Sociales. Departamento de Antropología.

Parsons, J. J. (1985). San Andrés y Providencia: una geografía histórica de las islas colombianas del Caribe. El Ancora Editores.

Pedraza, Z. (1984). We Was One Family: recopilación etnográfica para una antropología de Providencia. Monografía para optar al título de Antropóloga, Universidad de los Andes, Bogotá.

Rosberg, M. J. (1980). Pragmatic adaptation and idealistic intervention: an analytical description of development agencies within a context of political clientelism in 
San Andres Island, Colombia. Tesis doctoral, University of Wisconsin-Madison.

Secretaría de Agricultura y Pesca. Gobernación de San Andrés, Providencia y Santa Catalina. (2014). Informe final: resultado del análisis de encuesta socioeconómica a pescadores de San Andrés, Providencia y Santa Catalina. Archipiélago de San Andrés, Providencia y Santa Catalina.

Tereucán-Angulo, J., Briceño-Olivera, C. y Gálvez-Nieto, J. (2016). Equivalencia y valor en procesos de reciprocidad e intercambio entre los mapuches. Convergencia, 23(72), 199220.
Trujillo, A. (1984). Woman's work, hard works: trabajo de las mujeres de South West Bay y Lazy Hill, Providencia Isla. Tesis doctoral, Universidad de los Andes, Bogotá.

Vollmer, L. (1997). La historia del poblamiento del archipiélago de San Andrés, Vieja Providencia y Santa Catalina. San Andrés Isla: Ediciones Archipiélago.

Wilson, P. J. (2004). Las travesuras del cangrejo: un estudio de caso caribe del conflicto entre reputación $y$ respetabilidad. Unibiblos-U. Nal, Colombia. 